\title{
Theoretical substantiation of resource-saving system of recycle air clearing
}

\author{
Andreev Leonid \\ Mechanics and technology Institute \\ Federal state budgetary educational institution of higher \\ education "State agrarian University of Northern Zauralye" \\ Tyumen, Russia
}

\begin{abstract}
Cleaning and disinfection of recirculated air of livestock buildings are a critical factor in the formation of an optimal climate for agribusiness. The modern system of cleaning of the ventilation air does not allow one to analyze the composition of the air environment in the entire spectrum of harmful current components, which are calculated at the maximum values generating a hazard in the air of livestock premises without taking into account the physiological characteristics of animals, which leads to an increased energy process of cleaning and disinfection of the ventilation air. The developed and patented system of the automated regulation of the microclimate parameters allows real-time analysis of the current status of air environment quality of the working area livestock facilities and, if necessary, adjusting the operating parameters of the system clear key and disinfection of recirculation of ventilating air to maintain the main parameters of the air environment, such as concentrations of dust, microorganisms, and harmful gases (ammonia and hydrogen sulfide), lower values of maximum permissible concentrations. Mathematical modeling of the changes process in the concentration of harmful current components in the air helped to create a model of concentration dependence of such operating parameters of the system as the efficiency of cleaning and decontamination and the ventilation rate. The process design maintaining the air quality at the required level by the example of the pigsty showed that the vent, cleaning circulating air from dust with the required efficiency, allows one to achieve the required degree of purification of the air environment from ammonia and hydrogen sulfide. The application of the proposed system of the automated control of the microclimate parameters in livestock building will maintain the required parameters of air environment quality in combination with a reduction of energy consumption to maintain an optimal climate.
\end{abstract}

Keywords - microclimate; dust; hydrogen sulfide; ammonia; microorganisms; air cleaning; electro-filter.

\author{
Yurkin Vladimir \\ Mechanics and technology Institute \\ Federal state budgetary educational institution of higher \\ education "State agrarian University of Northern Zauralye" \\ Tyumen, Russia
}

The development of meat cattle breeding is a natural, objectively conditioned, economically and socially beneficial and the most promising direction of the revival of the meat complex of Russia.

The output of the maximum quantity of high quality products is complicated by the increased concentration of animals on complexes with high density, leading to a reduction in the room space per animal, which leads to a deterioration in the living conditions, expressed in a decrease in the quality of the air environment $[1,2,3]$.

The use of the most common ventilation systems is accompanied by large heat expenditure, in view of the fact that the energy consumption for creating a microclimate, namely the heating of the supply air, can reach $60 \%$ of the total energy costs of the enterprise. In addition to all that heat energy expense, the result is the exhausted polluted ventilation air released into the environment, which leads not only to a decrease in the energy efficiency of the enterprise, but also to an increase of the environmental load on nearby territories.

A promising and most effective way to solve this problem is the partial recirculation of ventilation air with simultaneous high-efficiency cleaning and disinfection. A comparison of the technical characteristics of the filters intended for cleaning the recirculation air showed that the two-stage wet electrostatic precipitator meets the most fully zootechnical requirements $[2,4]$.

Within a day, all living organisms experience the growth and decrease of various functions (for example, alternation of states of activity and rest) or periodic changes in the state of individual organs and entire organ systems. All these phenomena are associated with the alternation of day and night, that is, with processes that depend on the rotation of the globe. These changes are called day or seasonal cycles, depending on whether they are related to the alternation of day and night or alternation of periods of the year (Figure 1). If we consider that the recirculation air purification system includes energy-intensive ventilation equipment, such as electrofilters, fans, heaters, servo drives, intake valves, etc., we come to the question of regulating the efficiency of the recirculation air purification systems in order to save electricity, which is achieved by introducing an automation system in the structure of microclimate management. 
The introduction of a system for automated regulation of microclimate parameters will improve the smoothness and accuracy of the regulation of the microclimate parameters in the cattle-breeding premises, which will lead to an increase in the energy efficiency of livestock production, improvement of the conditions for keeping animals and raising the production culture.

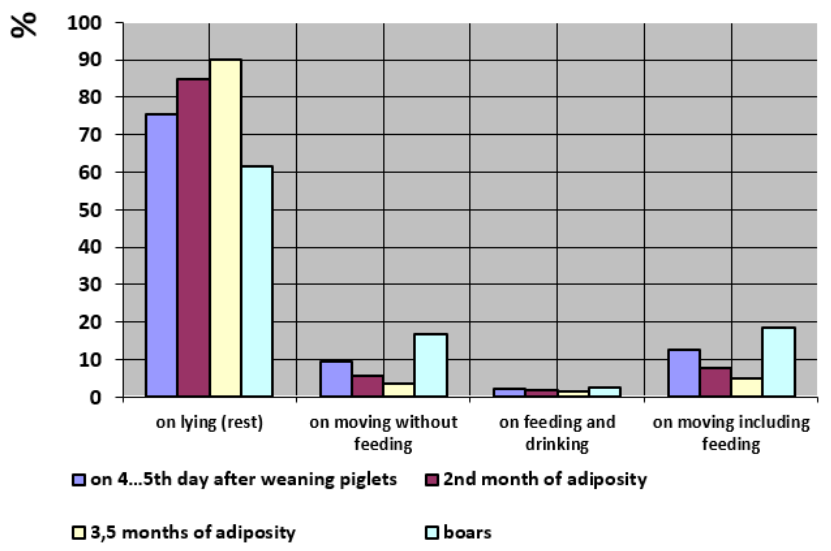

Fig. 1. Distribution of time of day (\%) in pigs when kept in pigsties

The core of automation system is the microclimate controller, which provides control and management of the environment in the cattle-breeding premises in real time. In the operating mode, the controller receives data on the state of the environment in the livestock house pulling data from various sensors and controls the actuators in accordance with the algorithm, supporting the specified parameters of the microclimate.

This paper considers a number of serial controllers SKOV (Denmark), models DOL 234 F and DOL 534; Big Dutchman (Germany), the Viper and Viper Touch models; DeLaval (Sweden), models DF1300, FL250F. The analysis of their technical characteristics showed that all of them have common functional characteristics (lighting control, measuring the temperature in the room, heating control, supply and exhaust fans, control of cooling and humidifying systems, control of the minimal air ventilation based on the level of $\mathrm{CO} 2$ and or NH3).

In turn, based on the literature [5], it is known that a significant number of dust and microorganisms are released in livestock premises, the concentrations of which the abovementioned devices do not control. In this connection, we should consider the question of controlling the level of dust and microorganisms in these rooms.

Also, it is known that there is the relationship between dust concentration and concentration of colony-forming particles (CFU) (Figure. 2) [6].

The dependence shown in Figure 2 can be described with sufficient accuracy by the expression [5]:

$$
n_{C F P}=0,0044 \cdot n_{\text {dust }}^{0,66}
$$

where $n_{\text {dust }}^{0.66}$ - number of dust particles with a limiting size of $0.5 \mu \mathrm{m}$ or more.
Thus, having the ability to control the concentration of dust, it is possible to monitor the concentration of CFU.

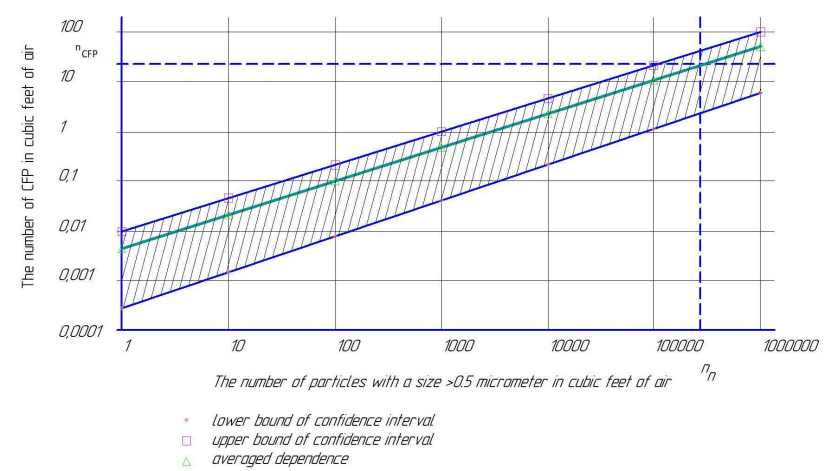

Fig. 2. Relationship of microbial air pollution and the number of aerosol particles

To solve the above-mentioned problem, a system of automated regulation of microclimate parameters in a cattlebreeding room was developed on the basis of the Arduino hardware platform (Figure 3), which includes a controller unit, which receives signals from gassing and dust sensors, and temperature and humidity sensors for internal and external air , electric drives of air dampers, the electric drive of the fan, a control system for the parameters of the corona discharge system of the electrostatic precipitator [7,8,9].

The system that is based on the readings of the sensors makes it possible to maintain the values of the air environment parameters of the cattle-breeding premises within specified limits.

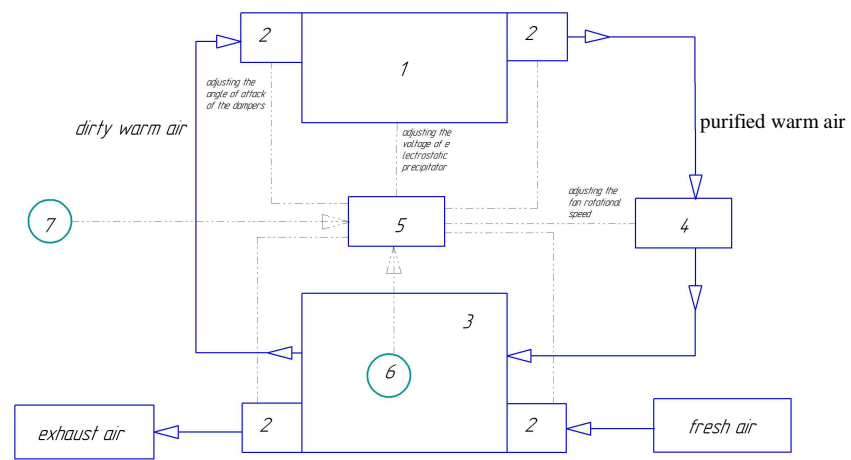

Fig. 3. System of automatic regulation of microclimate parameters: 1 electrofilter; 2 - actuator air damper; 3 - livestock house; 4 - fan motor; 5 controller block; 6 - subsystem of microclimate sensors (dust sensor, gassing sensor); 7 - environmental sensors.

The mathematical model of the process of controlling of harmful substances concentration in the air environment of the cattle-breeding room is constructed using known techniques $[10,11]$ on the basis of the structural block diagram of the air purification system in a closed volume, shown in Fig. 4. 


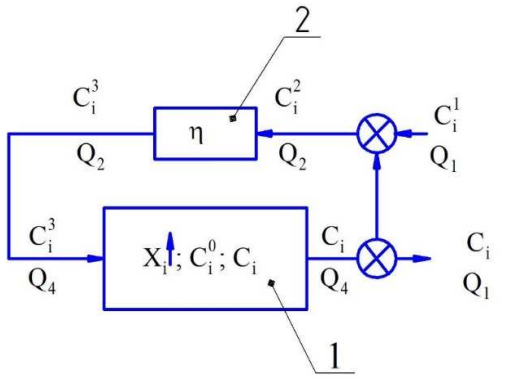

Fig. 4. Structural block diagram of an air purification system in a closed volume: 1 - closed volume (room, camera, etc.); 2 - recirculation filter

In the block diagram the following designations are accepted: V - volume (room, camera, etc.); Xi - specific release of the $\mathrm{i}$-th harmful component into the air environment of a closed volume; Q1 - the amount of air entering the system from the outside and being removed to the outside; Q4 - the amount of air entering the closed volume and being removed from the closed volume; $C_{1}^{0}, \mathrm{Ci}$ - respectively, the initial and current concentration of the $\mathrm{i}$-th harmful environment component of the closed volume; $\mathrm{C}_{\mathrm{i}}{ }^{1}, \mathrm{C}_{\mathrm{i}}{ }^{2}, \mathrm{C}_{\mathrm{i}}{ }^{3}$ - concentration of the i-th harmful component, respectively, in the external air entering the filter and the air removed from the filter; $\eta$ is the efficiency of air purification from the i-th harmful component of the air medium in the recirculation filter. [10].

$$
\mathrm{C}_{\mathrm{i}}^{2}=\left(\mathrm{C}_{\mathrm{i}}{ }^{1}+\mathrm{C}_{\mathrm{i}}\right) / 2
$$

Let the n-component of various harmful substances (carbon dioxide, ammonia, hydrogen sulphide, organic and inorganic dust, microorganisms - fungi, bacteria, viruses, thiols (mercaptans), etc.) be in the air of a closed volume. It is required to determine the dependence of the current concentration of the $\mathrm{i}$-th harmful component in a closed volume on the time, regime and design parameters of the system:

$$
\mathrm{C}_{\mathrm{i}}=\mathrm{f}\left(\eta_{\mathrm{i}} ; \mathrm{N}_{1} ; \mathrm{N} ; \ldots \ldots ; \mathrm{N}_{\mathrm{a}} ; \mathrm{t}\right)
$$
time.

$\mathrm{N}_{1}, \mathrm{~N}, \ldots$ regime and design parameters of the system; $\mathrm{t}$ is

In solving this problem, the following assumptions are made:

1) the i-th harmful component, generated in the air, is immediately and uniformly mixed with air and its concentration is the same throughout the room;

2) the filtration efficiency is constant and does not depend on the concentration of the i-th harmful component at the entrance of the electrostatic precipitator;

3 ) the specific allocation of the i-th harmful component inside the room is constant and does not depend on its concentration in the air environment of the room;

4) the change in concentration of the i-th harmful component in the air environment of the room due to natural processes is insignificant.

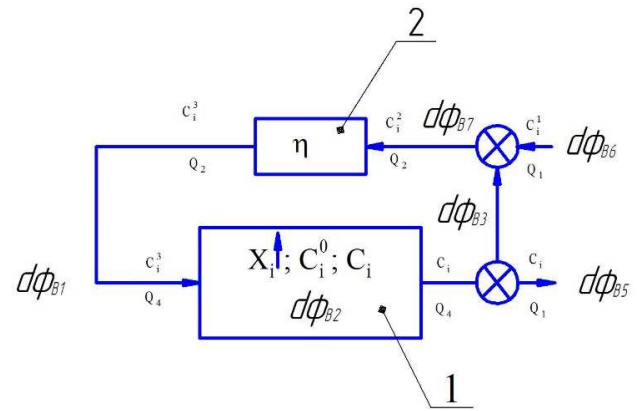

Fig. 5. Block diagram of a closed-circuit air purification system: 1 - closed volume (room, camera, etc.); 2 - recirculation filter

To determine the dependence (2.3), we use the above block diagram (Fig. 5). The equation of material balance for the i-th harmful component in the air of the room for the time interval in $\mathrm{t}, \mathrm{t}+\mathrm{dt}$, has the following form:

$$
\mathrm{d} \varphi_{\mathrm{v}}=\mathrm{d} \varphi_{\mathrm{v} 1+} \mathrm{d} \varphi_{\mathrm{v} 2-} \mathrm{d} \varphi_{\mathrm{v} 3}
$$

where $\mathrm{d} \varphi_{\mathrm{v}^{-}}$change in the amount of the i-th harmful component in the air in the room; $\mathrm{d} \varphi_{\mathrm{v} 1}, \mathrm{~d} \varphi_{\mathrm{v} 2}, \mathrm{~d} \varphi_{\mathrm{v} 3}$, accordingly, the amount of the i-th harmful component entering the room after the filter; discharged inside the room; removed from a room with exhaust air.

A part of the exhaust air can be recycled, can pass through the recirculation filter, can mix with the fresh air supply and, after cleaning, can enter the room again [11].

Therefore, in the general case:

$$
\mathrm{d} \varphi_{\mathrm{v} 1}=\mathrm{d} \varphi_{\mathrm{v} 7}(1-\eta)=\left(\mathrm{d} \varphi_{\mathrm{v} 6+} \mathrm{d} \varphi_{\mathrm{v} 3-} \mathrm{d} \varphi_{\mathrm{v} 5}\right)(1-\eta)
$$

where $\mathrm{d} \varphi_{\mathrm{v} 1}$ - the amount of the i-th harmful component entering the room; $\mathrm{d} \varphi_{\mathrm{v} 4^{-}}$the amount of the $\mathrm{i}$-th harmful

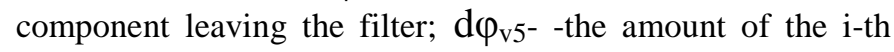
harmful ingredient emitted to the outside; $d \varphi_{\mathrm{v} 7}-\mathrm{t}$ the amount of the i-th harmful component coming from the room and from outside; $d \varphi_{v 6}$ - the amount of the i-th harmful component coming from outside; $\mathrm{d} \varphi_{\mathrm{v} 3}$ - the amount of the $\mathrm{i}$ th harmful ingredient coming out of the room;

Taking into consideration (2.5), the differential equation (2.3) can be written in the form:

$$
d \varphi_{v=[} d \varphi_{v 6+} d \varphi_{v 3-} d \varphi_{v 5]}(1-\eta)+d \varphi_{v 2-} d \varphi_{v 3}
$$

It should be noted that the recirculation of ventilation air can be carried out in two modes. By the first mode, we mean air recirculation in the usual sense of this process, namely: the process in which fresh air $\mathrm{Q}_{1}$ is continuously mixed with part of the air in room $\mathrm{Q}_{5}$, and an air mixture $\mathrm{Q}_{2}=\mathrm{Q}_{1}+\mathrm{Q}_{5}$ enters the room from the air inlets of the ventilation system. The condition $\mathrm{Q}_{2}=$ const is provided. The recirculation mode in this case is characterized by the recycling coefficient $\alpha$ [13]:

$$
\begin{aligned}
& \alpha=\frac{\mathrm{Q}_{5}}{\mathrm{Q}_{5}+\mathrm{Q}_{1}}=\frac{\mathrm{Q}_{5}}{\mathrm{Q}_{2}} \\
& 0 \leq \alpha \leq 1
\end{aligned}
$$

The second mode is such mode of internal recirculation in which fresh air is continuously mixed with air from the room, and the amount of admixed air can vary within wide limits. 
Therefore, this variation can be carried out in a wide range due to the change. This mode is characterized by the coefficient of the multiplicity of the internal recirculation of air N1, which is determined from the relation:

$$
\begin{aligned}
& \mathrm{N}=\frac{\mathrm{Q}_{1}}{\mathrm{~V}} \\
& 0 \leq \mathrm{N} 1 \leq \infty .
\end{aligned}
$$

In general, the air purification system can operate simultaneously in the normal and internal recirculation mode. With this mode, $\mathrm{N}_{1}>\mathrm{N}_{\alpha}$.

When the system is operating simultaneously in the mode of normal and internal recirculation $(0<\alpha<1$; N1 $>\mathrm{N} \alpha)$, for the components: $\mathrm{d} \varphi_{\mathrm{v}}, \mathrm{d} \varphi_{\mathrm{v} 5}, \mathrm{~d} \varphi_{\mathrm{v} 2}, \mathrm{~d} \varphi_{\mathrm{v} 3}, \mathrm{~d} \varphi_{\mathrm{v} 6}$

$$
\left.\begin{array}{rl}
d \varphi_{B} & =V d C_{i} \\
d \varphi_{66} & =C_{i}^{1} V N(1-a) d t \\
d \varphi_{62} & =X_{i} V d t \\
d \varphi_{65} & =C_{i} V N(1-a) d t \\
d \varphi_{63} & =C_{i} V N d t
\end{array}\right) .
$$

Substituting (10) into (4), and after carrying out a number of mathematical transformations we get:

$$
\begin{aligned}
& \quad C_{i}=e^{(N(1-\eta)-N(1-a)(1-\eta)-N) t}+C_{0}+e^{(N(1-\eta)-N(1-a)(1-\eta)-N) t} \times \\
& \times \frac{C_{i}^{1} N(1-\eta)-N(1-a)(1-\eta)+X_{i}}{(N(1-\eta)-N(1-a)(1-\eta)-N)}-\frac{C_{i}^{1} N(1-a)(1-\eta)+X_{i}}{(N(1-\eta)-N(1-a)(1-\eta)-N)} .
\end{aligned}
$$

Expression (11) shows the dependence of the current concentration of the i-th harmful component in a closed volume on the time $t$, regime $(X, a, N)$ and constructive $(\eta)$ parameters of the system:

$$
C_{\mathrm{i}}=f(\eta ; N ; a ; X ; t) .
$$

The analysis of expression (11) showed that the recycling factor $\alpha$ does not have a significant effect on the change in the concentration $\mathrm{Ci}$ of the harmfulness in the room. It is known from [16] that the value of $\alpha$ is limited, on the one hand, by the physiological need of animals for ventilated air enriched with oxygen, i.e., $a$ can not be higher than 0.87 , and, on the other hand, the need to increase the energy efficiency of the ventilation system, which requires an increase in $a$ to one (a $\rightarrow 1)$.

Designing a model of an automated system for controlling the microclimate parameters is given by the example of a room for keeping wean pigs.

For fattening young animals, the lair area in the machine tool is $0.5 \mathrm{~m}^{2}$ per head, and $0.7-0.8 \mathrm{~m}^{2}$ - for adult animals. Width and depth of the machine are $3.5 \mathrm{~m}$. Feeding front is 30 $\mathrm{cm}$.

The temperature in the animal fattening room is maintained in accordance with the age of the pigs.

In fatteners, sharp temperature fluctuations cannot be tolerated during the day, as the pigs are adjusted to large temperature fluctuations only when consuming additional feed. At a low temperature in the room, the body of a pig cannot adapt for a long time, and the weight of animals decreases. At temperatures below $10{ }^{\circ} \mathrm{C}$, feed intake per $1 \mathrm{~kg}$ of growth is increased by $20-30 \%$

In pig-fatteners per 1 ton of live weight, air exchange should be provided: in winter $-35-45 \mathrm{~m}^{3} \mathrm{~h}$, in summer - up to $60 \mathrm{~m}^{3} \mathrm{~h}$. Therefore, in summer, with a considerable number of animals in the room and with insufficient air exchange, the air temperature in the room rises to $28-30{ }^{\circ} \mathrm{C}$ which adversely affects the health of animals - heat transfer is disturbed, diseases of the respiratory system and digestion occur, and as a result, the growth and development of animals are delayed. To improve heat transfer, air exchange is increased in the room. The usual way to achieve this is to open the windows, doors, to increase the work of forced ventilation and to increase the speed of air movement to $1 \mathrm{~m} / \mathrm{s}$ or more.

The power of emission of pollutants from animal sites is composed of the emission capacities from each group of animals of the same species, united by a common process (maintenance, breeding or fattening) with the same diet and daily removal of manure, and is calculated by the formula:

$$
Q_{\text {overall }}^{\mathrm{i}}=Q_{\mathrm{vent}}^{\mathrm{i}}+Q_{\text {manure }}^{\mathrm{i}} \text {. }
$$

The release power $\left(Q_{n}^{i}\right)$ of the i-th substance is calculated by the formula:

or

$$
Q_{n}^{i}=Y_{n}^{i} \times M \times q, \mathrm{~g} / \mathrm{s}
$$

$$
Q_{n}^{i}=K \times Y_{n}^{i} \times M \times q, \text { ton/year }
$$

where $\mathrm{i}$ - conventional designation of pollutant.

For microorganisms, the formulas in the formulas are ks / s and 106 cells / year, respectively;

$\mathrm{n}$ - conventional designation of a group of animals of the same species, united by a common technological process;

$\mathrm{K}$ is the coefficient of transition from the dimension $(\mathrm{r} / \mathrm{c}$ ) to ( $\mathrm{m} /$ year), in formula (15), $\mathrm{K}=31.5$;

$y_{n}^{i}$ - the value of specific release of the i-th pollutant, established for animals of a certain type participating in the general technological process. It is necessary to choose the value of specific allocation taking into account the periodicity of removal of manure from the premises for keeping animals;

$\mathrm{M}$ - the number of animals participating in the general technological process;

$\mathrm{q}$ is the average mass in the centners of one animal from the group of animals participating in the general technological process. The product $\mathrm{N} \times \mathrm{q}$ can be replaced by the mass of all animals participating in the same technological process.

The maximum one-time $(\mathrm{g} / \mathrm{s})$ allocation is calculated similarly, but in this case all calculated data are selected with the maximum values.

Let us consider the parameters of the air environment by the example of a typical pig complex, a section of the reproductive workshop, in which there are 550 piglets. At a rate of $0.4 \mathrm{~m}^{2} /$ head [RD-APK 1.10.02.04-12 Methodological recommendations for the technological design of pig farms 
and complexes]. The average weight for entering the weaned piglet section is $20-23 \mathrm{~kg}$. Time of stay in the section is 53 days. Weight when sending from the section is $51-55 \mathrm{~kg}$. Section dimensions: height - 4 meters, width - 15 meters, length - 18 meters. Thus, the volume of the room is 1080 meters cubic, with an area of $270 \mathrm{~m}^{2}$. For zoo-hygienic requirements, the air exchange rate is $35 \mathrm{~m}^{3} / \mathrm{h} / \mathrm{c}$. Thus, the required air exchange is $3850 \mathrm{~m}^{3}$ on the day of entry into the section and $9625 \mathrm{~m}^{3}$ of the outlet from the section. Thus, it is necessary to ensure a multiplicity of air exchange $\mathrm{N}$ of not less than 3.8. Let us determine the amount $i$ of harmfulness in the room using the formula (13). For this room, according to known methods [5, 7], DMEF was calculated and modeled with the following parameters. The efficiency of air purification: from dust and aerosol particles - 95\%, from microorganisms $-77 \%$, from ammonia $-84 \%$, from hydrogen sulphide $-50 \%$. The voltage of the corona discharge, U1 steps $=9 \mathrm{kV}$; U2 steps $=13 \mathrm{kV}$. Supply voltage is $\mathrm{U}=220 \mathrm{~V}$; corona discharge working current, I1step $=6 \mathrm{~mA}$, I2step $=$ $13 \mathrm{~mA}$. Power is $\mathrm{P}=223 \mathrm{~W}$; volumetric air velocity (air capacity) is $L=4000 \mathrm{~m}^{3} / \mathrm{h}$. The speed of the air flow through the filter is $\mathrm{V}=2.2 \mathrm{~m} / \mathrm{s}$. The radius of the precipitation electrode is $\mathrm{R}=350 \mathrm{~mm}^{2}$. Living section of the filter is $\mathrm{S}=0.5$ $\mathrm{m}^{2}$.

For such electrostatic precipitators, it is permissible to increase the speed of the air flow through the electrostatic precipitator to $3 \mathrm{~m} / \mathrm{s}$ without loss of purification efficiency $\eta$. Thus, an efficient operation of the system with an air exchange rate $\mathrm{N}=5$ is possible.

From animals during the transitional period [RD-APK 1.10.02.04-12 Methodological recommendations for the technological design of pig farms and complexes] [16]:

$$
\begin{aligned}
& Q_{v e n t}^{N H 3}=43 \times 10^{-3} \times 550 \times 0,2 \times 3600=17 \mathrm{~g} / \text { hour } \\
& Q_{v e n t}^{H 2 S}=9,7 \times 10^{-3} \times 550 \times 0,2 \times 3600=3,8 \mathrm{~g} / \mathrm{hour} \\
& Q_{v e n t}^{\text {dust }}=56 \times 10^{-3} \times 550 \times 0,2 \times 3600=22,2 \mathrm{~g} / \mathrm{hour}
\end{aligned}
$$

From the manure-collecting channel during the transition period [10]:

$$
\begin{aligned}
& Q_{\text {manure }}^{N H 3}=107 \times 10^{-3} \times 550 \times 0,2 \times 3600=42,6 \mathrm{~g} / \text { hour } \\
& Q_{\text {manure }}^{H 2 S}=34,8 \times 10^{-3} \times 550 \times 0,2 \times 3600=13,8 \mathrm{~g} / \text { hour }
\end{aligned}
$$

Thus, we obtain:

$$
\begin{gathered}
Q_{\text {overal }}^{N H 3}=17+42,6=59,6 \mathrm{~g} / \text { hour } \\
Q_{\text {overal }}^{H 2 S}=3,8+13,8=17,6 \mathrm{~g} / \text { hour }
\end{gathered}
$$

Thus, the specific release of the $\mathrm{i}$-th harmful component $\mathrm{Xi}$ into the air of this room with a volume of $1080 \mathrm{~m}^{3}$ is $\mathrm{Xi}=\mathrm{QV}$ in ammonia $55.2 \mathrm{mg} / \mathrm{h} / \mathrm{m}^{3}$; hydrogen sulphide $16.3 \mathrm{mg} / \mathrm{h} /$ $\mathrm{m}^{3}$; by dust of $20.6 \mathrm{mg} / \mathrm{h} / \mathrm{m}^{3}$.

The maximum permissible concentration of ammonia is 20 $\mathrm{mg} / \mathrm{m}^{3}$; hydrogen sulphide is $10 \mathrm{mg} / \mathrm{m}^{3}$; dust $6 \mathrm{mg} / \mathrm{m}^{3}[7,8,9$, $15]$.

Using expression (11), we simulate the process of changing the concentration of hydrogen sulfide and ammonia as a function of time (Pic. 6, 7). From the previous calculations it follows that the air exchange rate for the selected pig-fattening facility is $\mathrm{N}=3,8$, the recycling coefficient is $\mathrm{a}=0.87$, the specific hydrogen sulfide release is
$\mathrm{X}=16.3 \mathrm{mg} / \mathrm{h}^{\circ} \mathrm{m}^{3}$, the specific ammonia emission is $\mathrm{X}=55.2$ $\mathrm{mg} / \mathrm{h} \cdot \mathrm{m}^{3}$.

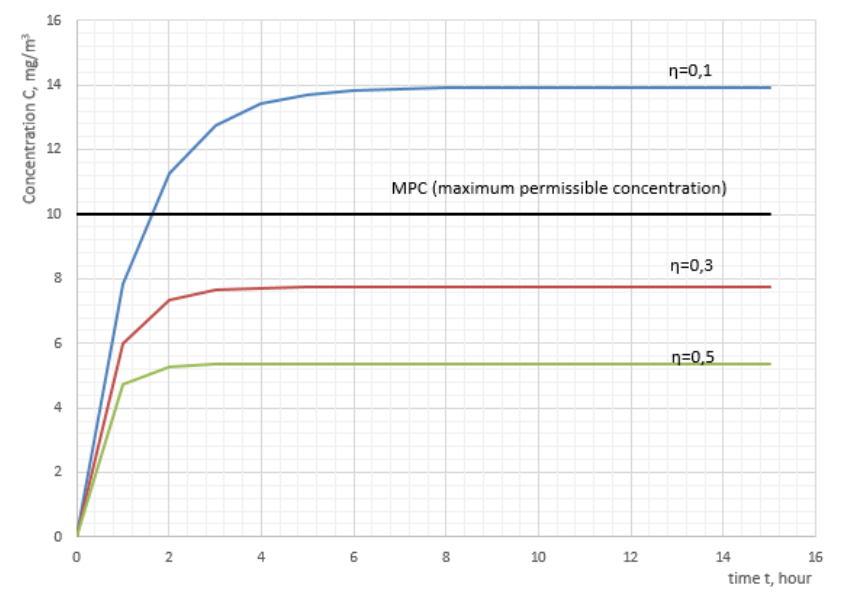

Fig. 6. $\mathrm{C} \mathrm{H}_{2} \mathrm{~S}=\mathrm{f}(\mathrm{t}), \mathrm{N}$-const $(3,8)$, a-const $(0,87)$, $\eta$-var $(0,1 ; 0,3 ; 0,5), \mathrm{X}=$ $16,3 \mathrm{mg} / \mathrm{h} / \mathrm{m}^{3}$.

It can be seen from the graph in Fig. 6 that with a purification efficiency of $\eta=0.5$, the hydrogen sulfide concentration does not exceed the maximum allowable concentrations.

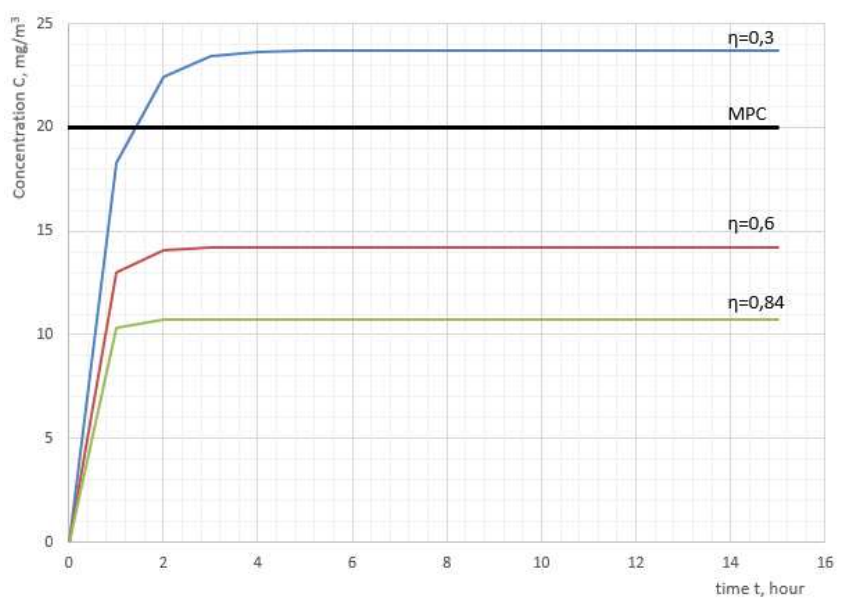

Fig. 7. $\mathrm{CNH}_{3}=f(t), \mathrm{N}$-const (3.8), a-const (0.87), $\eta$-var (0.3, 0.6, 0.84), $\mathrm{X}=$ $55.2 \mathrm{mg} / \mathrm{h} \cdot \mathrm{m}^{3}$

It can be seen from the graph in Figure 7 that, with a purification efficiency of 0.84 , the ammonia concentration does not exceed the maximum allowable concentration, so for a given animal house the efficiency of cleaning from hydrogen sulfide, equal to 0.5 , and from ammonia, equal to 0.84 , will be sufficient to maintain the concentration of hydrogen sulphide and ammonia within acceptable limits..

Using expression (11), it is also possible to simulate the process of changing the dust concentration as a function of time, knowing the multiplicity of the air exchange $\mathrm{N}$, the recirculation factor $a$, and the specific dust release $\mathrm{X}=20.6$ $\mathrm{mg} / \mathrm{h} \cdot \mathrm{m}^{3}$ (Fig. 8). 


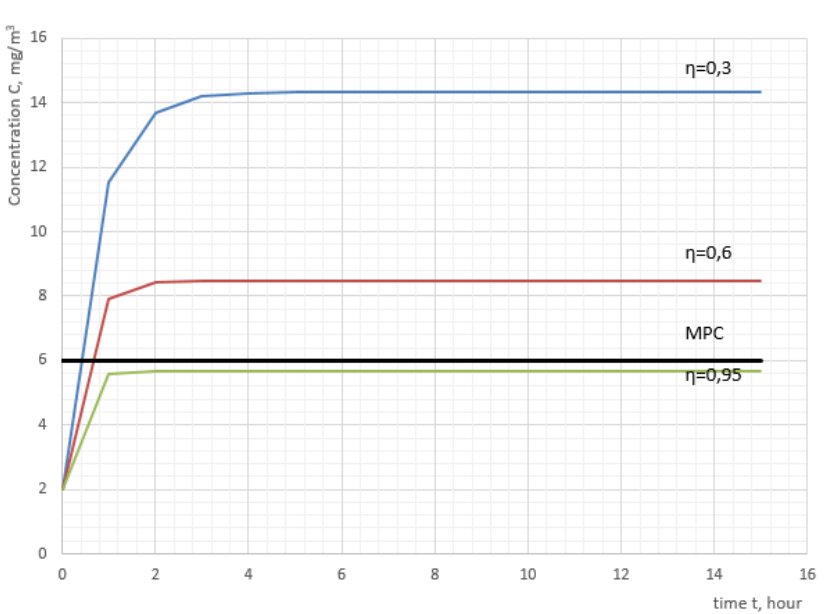

Fig. 8. Spray $=\mathrm{f}(\mathrm{t}), \mathrm{N}$-const (3.8), a-const (0.87), $\eta$-var (0.3, 0.6, 0.95), $\mathrm{X}=$ $20.6 \mathrm{mg} / \mathrm{h} \cdot \mathrm{m} \mathrm{m}^{3}$

It can be seen from the graph in Fig. 8 that the reduction of the dust concentration below the maximum permissible concentrations is achieved with the efficiency of the electrostatic precipitator for cleaning the air environment from dust reaching a value of 0.95 .

The relationship between $\eta$ and $N$ at the set value of the ith concentration of $\mathrm{Ci}$ in the livestock house, which should be below the maximum permissible concentration, is reflected in the graph $\mathrm{N}=\mathrm{f}(\eta)$ (Fig. 9).

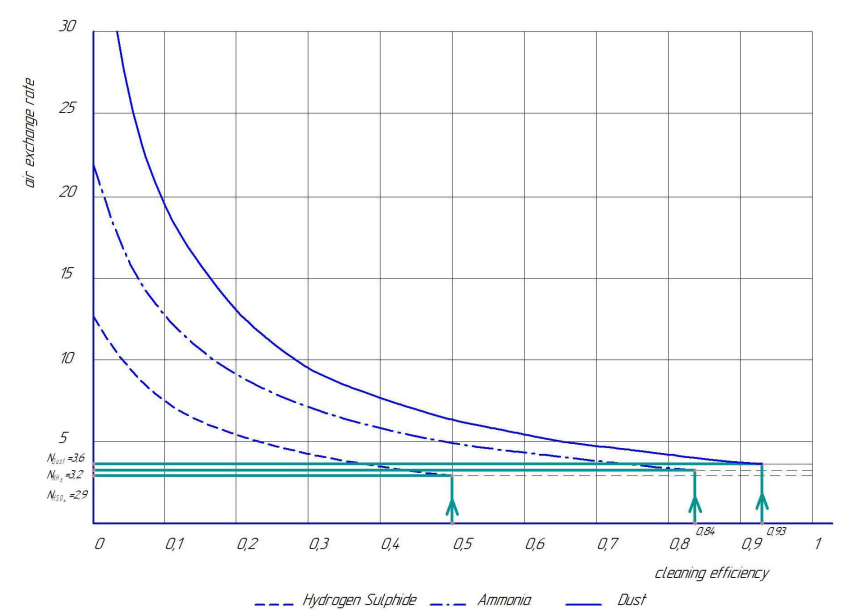

Fig. 9. The relationship between $\eta$ and $\mathrm{N}$ at the set value of the i-th concentration of $\mathrm{Ci}$ in the livestock house.

From the diagram in Fig. 9 it can be seen that the air exchange rate, necessary for cleaning the recirculation air from the dust, will "overlap" the air exchange rates needed to purify the recirculation air from hydrogen sulphide and ammonia with the required air purification efficiency. Thus, by cleaning the ventilation circulation air from dust with the required efficiency, the necessary degree of air purification from ammonia and hydrogen sulfide is achieved.

Analysis of literature data on the ethology of animals revealed a cyclic nature of the activity of animals during a certain period of time (day, season), which affects the microclimate of the livestock house.
The system of automated regulation of microclimate parameters (SARP-M) has been developed and patented, allowing to monitor and regulate the air environment parameters in real time in order to reduce energy costs for creating the optimal microclimate in the cattle-breeding environment.

Based on the mathematical analysis of the processes of generation of harmful substances, the dynamics of the movement of air currents in the livestock house and the processes of reducing the concentrations of harmful substances in the purification system of recirculation air, a mathematical model of the process of monitoring the concentration of harmful substances in real time mode has been developed.

\section{References}

[1] S.I. Ivanov and G.N. Samarin, "Energy efficient microclimate formation," Rural mechanic, vol. 1(47), pp. 28-29, March 2013.

[2] A.G. Vozmilov, R.Yu. Ilimbetov, D.V. Astafev "The Usage of Ozone in Agriculture Technological Processes," 2nd International Conference on Industrial Engineering, Applications and Manufacturing (ICIEAM) Proceedings, 2016.

[3] S.V. Os'kin, V.A. Didych, A.G. Vozmilov, "Key Ways of Energy Saving in Pump Units for Melioration and Irrigation Systems," International Conference on Industrial Engineering, Applications and Manufacturing (ICIEAM), 2017.

[4] A.A. Andreev, A.G. Vozmilov, V.A. Kalmakov, "Simulation of lithium battery operation under severe temperature conditions," International Conference on Industrial Engineering, Procedia Engineering vol. 129, pp. $201-206,2015$.

[5] R.Yu. Ilimbetov, V.V. Popov, A.G. Vozmilov, "Comparative analysis of "NGTU - Electro" electric car movement processes modeling in MATLAB Simulink and AVL Cruise software,'International Conference on Industrial Engineering Procedia Engineering vol. 129, pp. $879-885,2015$.

[6] A.G. Vozmilov, R.Yu. Ilimbetov, D.V. Astafev, "Theoretical and Experimental Studies of the Effectiveness of an Electrostatic Air Cleaning Filter," 2nd International Conference on Industrial Engineering, Applications and anufacturing (ICIEAM), 2016.

[7] A.S. Kizurov, I.P. lapshin, S.N. Kokoshin, "Differentiated drying of the mixtures colloidal components used in the construction of underground infrastructure," Procedia Engineering vol. 165, pp. 806 - 816, 2016.

[8] S.N. Kokoshin, N.N. Ustinov, B.O. Kirgincev, "The use of flexible tubular elements of the overhaul and tunnels reconstruction," Procedia engineering, vol. 165, pp. 817-828, 2016.

[9] S.N. Kokoshin, S.M. Sozonov, I.A. Shestopalov, "Theoretical justification of reducing soil adhesion to the surfaces of the excavator working body at creation underground infrastructure," Procedia engineering, vol.165, pp. 829-838, 2016.

[10] L.N. Andreev, N.I. Smolin, B.V. Zherebtsov, "Prerequisites for improving the efficiency of a wet single-zone electric filter," Philosophical and literary Journal Logos, vol. № 2. , pp. 3-4, 2013.

[11] L.N. Andreev and V.V. Yurkin, "Energy efficient technologies of microclimate creation in animal husbandry," Proceedings of the International Conference "Actual Issues of Mechanical Engineering" 2017 (AIME 2017) doi:10.2991/aime-17.2017.11

[12] A.G. Vozmilov, L.N. Andreev, D.V. Astaf'ev, B.V. Zherebtsov, A.A. Dmitriev, "Results of production tests of a wet electrostatic precipitator," Vestnik Krasnoyarskogo gosudarstvennogo agrarnogo universiteta, vol. №8, pp. 185-191, 2013.

[13] F.Ya. Izakov, V.B. Fayn, "O the calculation of a system for cleaning air from dust in ventilated livestock buildings," Trudy ChIMESKh, vol. 81, pp. 130-133, 1974.

[14] A.A. Andreev, A.G. Vozmilov, V.A. Kalmakov, "Development of the Experimental Assembly for Studying the System Maintaining Battery Optimal Temperature," International Conference on Industrial Engineering, Applications and Manufacturing (ICIEAM), 2017. 
[15] V.V. Khramtsov, G.P. Tabakov, "Zoohygiene with the basics of veterinary medicine and sanitation," M.: Kolos; 2004.

[16] RD-AIC 1.10.02.04-12 Methodological recommendations for the technological design of pig farms and complexes 